\title{
A Cross-Cultural Comparison Of Factors Influencing Self-Scan Checkout Use
}

Jana Schliewe, Ilmenau University of Technology, Germany

Kerstin Pezoldt, Ilmenau University of Technology, Germany

\begin{abstract}
The purpose of this paper is to study the factors influencing the acceptance of self-scan checkouts in Russia, an emerging East European transition economy, and Germany, an established Western European market. In particular, the paper seeks to examine the potential effects of social pressure, self-efficacy and technology anxiety on the self-scan checkout usage decision. Additionally, the article attempts to find out whether firms need to adapt their strategies of market launch to the special needs of the different countries. The design of this study was empirical. Data were collected from students in two universities in Germany and Russia. The findings of the study clearly show the differences between the two countries. The German participants have a lower level of social pressure and technology anxiety whereas the Russian participants have a lower level of self-efficacy.
\end{abstract}

\section{INTRODUCTION}

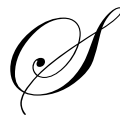

elf-service technologies (e.g. automated teller machines, ticket machines or online shopping) are omnipresent in today's life. They are defined as technological interfaces that help users to generate a service without direct assistance from service employees (Meuter et al., 2000). Self-scan checkouts are an example of an innovative self-service technology. They are checkouts where customers scan the barcodes of their products, pay for the products and put them into bags on their own, without the help of service employees. It is a young technology and still not very common in Germany and Russia. Retailers can save up to $25 \%$ of their process cost in high-wage countries and they can benefit from a reduced staff requirement if they implement this technology (Wincor Nixdorf, 2007). The benefit to the customer is a reduced checkout time because stores are often able to run efficiently two to six self-scan checkout units where traditionally only one cashier was possible. All these advantages are strong incentives for companies to install and implement self-scan checkouts.

The implementation of new technologies is very cost- and time-intensive. To avoid loss of investment companies have to understand the reasons for acceptance or avoidance before they implement the technologies (Curran et al., 2003). The crucial success factor is the knowledge about the intention of the customers to use the new technology. The usage intention is determined by the individual characteristics of the customer.

Psychological constructs, like self-efficacy, social pressure and technology anxiety, have been identified as important determinants of technology acceptance (Eastin, 2002; Meuter et al., 2003; Meuter et al., 2005; Nysveen et al., 2005). However, most research about technology acceptance relies on the customer behaviour in the USA and Western Europe, whereas it is still not known whether the usage of self-service technologies is similar in other cultures. Cross-cultural differences in self-efficacy, social pressure and technology anxiety for Western and Eastern European markets have not been investigated yet, though it is known that the psyche is influenced by the culture (Mueller/Gelbrich, 2004). Only a few efforts to estimate the usage of self-service technologies in non-Western markets have been made (Nilsson, 2007). This lack of cross-cultural comparisons represents a critical barrier for service firms in Western markets, which plan to offer their services as self-service technologies in an emerging market. The emerging East European transition economies are very interesting for firms because they still have a high growth potential of the economy in comparison with the stagnating growth rates in Western European economies. For the year 2010 the gross domestic product (GDP) of Russia is predicted to be at a level between 5.0 and 5.5\% (World Bank, 2010). This economic growth represents a new chance for Western firms that plan to 
implement or sell self-scan checkouts. Because the world economy is becoming increasingly global, there is a need for more cross-cultural studies.

Hence, this study examines the differences between consumers in two different countries, Germany and Russia. Germany and Russia were chosen because of their cultural differences: Germany represents an established Western European market, whereas Russia is an emerging East European transition economy.

Therefore, the purpose of this study is to examine the cultural differences in factors influencing the acceptance of self-scan checkouts. Based on these results practical implications are deduced. Because of existing differences between people in Germany and Russia in respect of their buying behaviour (Schmidt, 2004), it can be assumed that there are also differences in the acceptance of self-scan checkouts. Drawing on the existing findings of the technology-acceptance theory, key acceptance factors are introduced. The focus lies on self-efficacy, technology anxiety and social pressure influencing the intention to use self-scan checkouts. With an increased understanding of these constructs, retailers will be better prepared to manage the implementation of self-scan checkouts in Germany and Russia. To explore these issues we pose two research questions:

- $\quad$ How do German and Russian consumers evaluate technology anxiety, social pressure and self-efficacy in relation to using self-scan checkouts?

- What are the differences and similarities between the consumers in these two countries?

\section{POSITIONING WITHIN THE LITERATURE}

The adoption of technological products in general and the acceptance of self-service technologies in particular are often explained by the Technology Acceptance Model (TAM) (Davis, 1989). The Technology Acceptance Model shows how users accept and use a new technology. A number of factors influence the decision about how and when to use it. The Technology Acceptance Model may help us understand how consumers evaluate users' technology acceptance and to predict the determinants of individual behaviour toward a given system (Agarwal/Prasad, 1997).

The large field of technology acceptance can be divided into two main research streams (Lockett/Littler, 1997). One research field investigates users' perception of several characteristics of new technology, like relative advantage, compatibility, complexibility, trialibility and observability (Rogers/Shoemaker, 1971; Rogers, 2003). The second approach considers the impact of the personal characteristics (e.g. self-efficacy, perceived control, demographics) of the user (Eastin, 2002; Meuter et al., 2003; Meuter et al., 2005; Nysveen et al., 2005). It is important to identify the characteristics of the customers influencing the acceptance (Anselmsson, 2001) because customers vary in their intention to use innovative self-service technologies. Unfortunately, the contribution of the demographic characteristics is not particularly satisfactory, so additional factors were investigated, like psychological constructs. Psychological factors facilitating technology acceptance are social pressure, self-efficacy and technology anxiety (Eastin, 2002; Meuter et al., 2003; Meuter et al., 2005; Nysveen et al., 2005).

Social pressure (SP) is defined as the individual's perception that people who are important to her/him, like family, friends or supervisors, think s/he should or should not behave in a particular way, like using self-service technologies (Robertson, 1967; Davis, 1993; Venkatesh/Davis, 2000; Aronson et al., 2008). There is a positive relationship between social pressure and intention to use self-service technologies if the social environment of the person supports this technology (Hung et al., 2002). In numerous studies based on TAM it is shown that the social norm influences technology acceptance (Karahanna et al., 1999; Schepers/Wetzels, 2006) and behavioural intention to use online shopping (Venkatesh/Davis, 2000; Yoh et al., 2003), mobile chat services (Nysveen et al., 2005) and financial self-service (Curran/Meuter, 2007).

Self-efficacy (SE) describes the individual's assessment of his or her abilities to deal with a specific situation (Bandura, 1977) and has a positive effect on the intention to use self-service technologies. Customers with higher self-efficacy can be expected to have more confidence in their ability to use self-scan checkouts and may be familiar with these technologies. Specifically, Meuter et al. (2005) showed that self-efficacy is one of the key factors inducing self-service technology acceptance. Similar findings for several self-service technologies are reported by 
Eastin (2002) and Rose (2007). Self-efficacy is strongly influenced by technology anxiety (Compeau et al., 1999).

Technology anxiety (TA) relates to the level of anxiety experienced by an individual confronted with the decision to use a new technology (Igbaria/Parasuraman, 1989). It is one of the biggest problems in relation to self-servicetechnology acceptance (Ostrom et al., 2002). The intention to use self-service technologies is negatively affected by technology anxiety. Meuter et al. (2003) have shown that technology anxiety is a more important predictor of using self-service technologies than demographic determinants. Studies have proved this influence on online shopping (Kim/Forsythe, 2008).

In order to be able to draw conclusions for market launch strategies we measure the intention to use selfscan checkouts. Intention to use self-scan checkouts is based on the behavioural intention, and is defined as the degree of one's aim to act in a particular way (Fishbein/Ajzen, 1975).

\section{HYPOTHESES}

In this study, we examine technology acceptance in Germany and Russia. It has been shown that cultural aspects play an important role in determining technology acceptance (Van Everdingen/Waarts, 2003; Nilsson, 2007). Hofstede's (2001) cultural framework consists of four dimensions: individualism, power distance, uncertainty avoidance and masculinity. Prior studies have shown that individualism and uncertainty avoidance are the two variables that are important to consumers' acceptance of innovations in different cultures (van Everdingen/Waarts, 2003; Lim et al., 2004).

People in individualistic cultures see themselves as more independent persons than people in collectivistic cultures, who feel they belong to a group and are responsible for each other (Yeniyurt/Townsend, 2003). According to Steenkamp et al. (1999), consumer innovativeness is valued positively in cultures with a high level of individualism and negatively in cultures with a low level of individualism. People in cultures with a high level of individualism are more willing to adopt innovations than people in countries with a low level (Steenkamp et al., 1999; van Everdingen/Waarts, 2003).

People in cultures with a high level of uncertainty avoidance have a low level of willingness to change their established patterns (Steenkamp et al., 1999). Using new technologies is risky and uncertain. Cultures with a higher level of uncertainty avoidance are less likely to be early users of new products and technologies (Park/Jun, 2003).

The two countries of interest in this paper exhibit different levels of uncertainty avoidance and individualism. The Germans are characterized as having a high level of uncertainty avoidance (index: 65) and individualism (index: 67) (Hofstede, 2001). In comparison, Russians are characterized as possessing a higher level of uncertainty avoidance (index: 75) and as having a lower level of individualism (index: 47). Because of the higher level of uncertainty avoidance and the lower level of individualism in Russia, Russian consumers would not be expected to be as eager as German consumers to use self-service technologies. Based on these cultural differences we conceive the following hypotheses:

H1. Russian students have a higher level of social pressure than German students do.

H2. Russian students have a lower level of self-efficacy than German students do.

H3. Russian students have a higher level of technology anxiety than German students do.

\section{METHODOLOGY}

\section{Sample}

Data were collected from 267 university students in Germany (Ilmenau) and Russia (St Petersburg), who were asked to complete a questionnaire about self-scan checkouts. There were 46 men and 57 women in the German sample and 79 men and 85 women in the Russian sample, making it a roughly equal division by gender. The average age of the respondents was 20.51 (German 21.98, Russian 19.59) years. To ensure functional equivalence and to rule out demographic and socioeconomic differences as rival explanations for our results, we used university students in 
both countries. Another reason for choosing students as participants in this study is their relevance as customers. They are better educated and more likely to be innovators and early adopters of new technologies than non-students (Rogers, 2003). Germany and Russia were chosen because of their cultural differences: Germany represents an established Western European market, whereas Russia is an emerging East European transition economy.

\section{MEASURES}

Social pressure was measured using the adapted scale from Bhattacherjee (2000). The respondents were asked to rate their level of persuasibility by people who are important to them. Self-efficacy was measured using a scale adapted from Compeau and Higgins (1995) and Pedersen (2005). The measures asked the subjects to express their level of confidence in their own abilities to perform a specific behaviour. Technology anxiety was measured with items adopted from Igbaria and Parasuraman (1989). The respondents were asked to express their level of anxiety and technological skills related to using technology. For all the concepts the respondents were asked to rate their level of agreement with statements using seven-point scales ranging from "strongly disagree" to "strongly agree". The scale reliabilities were high, with Cronbach's alphas of $0.814,0.825$ and 0.894 for social pressure, selfefficacy and technology anxiety, respectively. The intention to use self-scan checkouts was measured using sevenpoint semantic differential items with endpoints likely/unlikely, possible/impossible and I would not like to/I would like to (Fishbein/Ajzen, 1975). In addition, the Cronbach's alpha of the intention to use self-scan checkouts is high, with 0.896 . Together, these results suggest that the scales have high internal consistencies and are reliable measures.

\section{STUDY RESULTS}

In order to address our research question we compare the mean ratings of the measurement items for social pressure, self-efficacy and technology anxiety across Germany and Russia. We use the t-test, and in the case of heterogeneous variances where the t-test leads to biased results, we use the Welch test. Due to the law of large numbers, the necessary normal distribution can be assumed for subsamples greater than 50, which is fulfilled here. The analyses of the constructs social pressure, self-efficacy and technology anxiety derived by factor analyses reveals significant differences in the mean values for German and Russian respondents, with significance levels of 0.003, 0.032 and 0.018, respectively. Due to heterogeneous variances, the Welch test has been used for all three constructs. In conjunction with the mean values of the standardized constructs shown in Table 1, these results provide support for all three hypotheses.

In order to assess the relationship strength of response behaviour comparisons we use Cramer-V. The Cramer-Vs of social pressure, self-efficacy and technology anxiety are $0.269,0.250$ and 0.180 , respectively, suggesting a mean or weak dependence of the constructs from culture. Table 1 contains Cramer-V and the significance of response behaviour differences measured by the $\chi^{2}$ test. The analyses of self-efficacy and social pressure show statistically significant differences with 0.010 and 0.004 , respectively. Technology anxiety shows with 0.196 no significant difference, even though the significance level is small.

Furthermore, Table 1 provides a closer look at the measures for all the items. We found significant mean value differences for 11 items (SP3-5, SE1-3;5;6 and TA1;7;8) and 10 significant response behaviour differences (SP2-5, SE1-3;5 and TA1;8). SP2 shows no significant mean value difference but a distinct response difference. The reason is a more extreme response in Germany than in Russia. SE6 and TA7 show a weak response difference even though the mean values are slightly different. SE3 shows a significant but opposite tendency to the other items of self-efficacy, attenuating hypothesis 2 . All the other items support the corresponding hypotheses. The measurement of the intention to use self-scan checkouts reveals no significant difference in mean value as well as in response behaviour. The mean values (G: 4.54 and R: 4.67 ) show a slightly positive intention to use the technology for both countries. The Cramer-V shows with 0.150 a small difference in response behaviour. 
Table 1

Overview of the significance of differences between Germany and Russia. The mean values of the answers for the

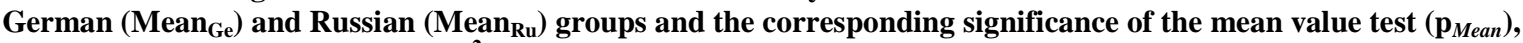
Cramer-V and significance of the $\chi^{2}$ test $\left(p_{\chi_{2}}\right)$. Significant differences are marked with bold numbers. The asterisk denotes the Welch test.

\begin{tabular}{|c|c|c|c|c|c|}
\hline Item & Mean $_{\mathrm{Ge}}$ & Mean $_{\mathrm{Ru}}$ & $p_{\text {Mean }}$ & Cramer-V & $p_{\gamma 2}$ \\
\hline Social pressure & -0.252 & 0.155 & $0.003 *$ & 0.269 & 0.004 \\
\hline $\begin{array}{l}\text { SP1: The people who are important to me would think I should use } \\
\text { SSTs. }\end{array}$ & 3.66 & 3.72 & 0.771 & 0.087 & 0.919 \\
\hline SP2: It is expected that people like me would use SSTs. & 4.58 & 4.65 & $0.723^{*}$ & 0.357 & 0.000 \\
\hline SP3: People I look up to would expect me to use SSTs. & 3.39 & 3.98 & $0.002 *$ & 0.270 & 0.004 \\
\hline $\begin{array}{l}\text { SP4: Most people who are important to me would approve of using } \\
\text { SSTs. }\end{array}$ & 3.60 & 4.45 & 0.000 & 0.319 & 0.000 \\
\hline $\begin{array}{l}\text { SP5: The people who are important to me would agree that using SSTs } \\
\text { is a good thing. }\end{array}$ & 3.76 & 4.24 & $0.004 *$ & 0.266 & 0.005 \\
\hline Self-efficacy & 0.161 & -0.101 & $0.032 *$ & 0.250 & 0.010 \\
\hline SE1: I could use SSTs without the help of others. & 5.99 & 5.26 & $0.000 *$ & 0.283 & 0.002 \\
\hline SE2: I could use SSTs if I had never used them before. & 5.30 & 4.76 & 0.010 & 0.221 & 0.042 \\
\hline SE3: I could use SSTs if I could call someone for help if I got stuck. & 3.39 & 4.71 & 0.000 & 0.389 & 0.000 \\
\hline SE4: I could use SSTs if no one showed me how to do it first. & 5.06 & 4.96 & 0.671 & 0.156 & 0.370 \\
\hline SE5: I could use SSTs on my own. & 6.03 & 5.23 & $0.000 *$ & 0.280 & 0.002 \\
\hline SE6: I could use SSTs if I had seen someone else using them before. & 5.23 & 4.80 & 0.042 & 0.180 & 0.197 \\
\hline Technology anxiety & -0.171 & 0.107 & $0.018 *$ & 0.180 & 0.196 \\
\hline TA1: I am unconfident that I can learn technology-related skills. & 1.48 & 2,10 & $0.000 *$ & 0.293 & 0.001 \\
\hline TA2: I have difficulty understanding most technological matters. & 2.18 & 2.32 & 0.454 & 0.165 & 0.296 \\
\hline $\begin{array}{l}\text { TA3: When given the opportunity to use technology, I fear I might } \\
\text { damage it in some way. }\end{array}$ & 2.27 & 2.38 & 0.558 & 0.136 & 0.549 \\
\hline TA4: I feel apprehensive about using technology. & 2.15 & 2.21 & 0.716 & 0.123 & 0.675 \\
\hline TA5: Technological terminology sounds like confusing jargon to me. & 2.31 & 2.46 & 0.396 & 0.155 & 0.376 \\
\hline $\begin{array}{l}\text { TA6: I hesitate to use technology for fear of making mistakes I cannot } \\
\text { correct. }\end{array}$ & 2.36 & 2.45 & 0.650 & 0.117 & 0.720 \\
\hline TA7: I have avoided technology because it is unfamiliar to me. & 1.71 & 2.23 & $0.001 *$ & 0.212 & 0.063 \\
\hline TA8: I am not able to keep up with important technological advances. & 1.74 & 2.62 & $0.000 *$ & 0.395 & 0.000 \\
\hline Intention to use self-scan checkouts & 4.54 & 4.67 & 0.579 & 0.150 & 0.422 \\
\hline
\end{tabular}

\section{DISCUSSION OF THE RESULTS}

This study focuses on the factors influencing the intention to use self-scan checkouts in a Western market like Germany and an Eastern transition market like Russia. Although support was received for the hypotheses of our study, some surprising findings were also revealed.

Differences between the two countries were shown by the analysis of social pressure defined as the respondent's perception that people who are important to her/him think s/he should act in a particular way (Cramer V: 0.269). The mean of the German sample is lower than the Russian one, which means that for Russian students the social environment is a more important determining factor of technology acceptance than for the German students ( $M G: 3.8 ; M R: 4.2$ ). More precisely: we can find the greatest difference between the countries for item SP.3 (M G: 3.39; M R: 3.98). Nearly $60 \%$ of the German students answered in a neutral way and $30 \%$ of the Germans strongly disagreed with the statement that "People I look up to would expect me to use SSTs". On the other hand, more than $70 \%$ of the respondents in Russia answered neutrally, nearly 13\% strongly agreed and 13\% strongly disagreed with this statement. There is no significant difference for item SP.1 (MW G: 3.66; MW R: 3.72). Item SP.2 "It is expected that people like me would use SSTs" (MW G: 4.58; MW R: 4.65) has no significant difference in mean value; however, the $\chi^{2}$ test indicates a difference in the response behaviour. In fact, the Russian students respond more neutrally while the German students respond more extremely. These findings are congruent with previous research, which mentioned that people in countries with a lower level of individualism such as Russia are more group-oriented than people in countries with a high level of individualism like Germany (Steenkamp et al., 1999; van Everdingen/Waarts, 2003). The social environment is more important for the Russian than for the German respondents. People who live in a technology-friendly social environment are more willing to use self-scan 
checkouts than people in a technology-unfriendly social environment are. Due to the positive tendency of the intention to use self-scan checkouts, we assume a perceived technology-friendly environment for the respondents in both countries.

In addition, the analysis of self-efficacy shows cultural differences (Cramer V: 0.250). The results of the analysis reveal that the German students have a higher mean for self-efficacy than the Russian students do ( $M W G$ : 5.17; $M W R: 4.95$ ). A closer look at the items shows that the greatest differences can be found for item SE.3 (MW G: 3.39; MW R: 4.71; Cramer V: 0.389), but with an opposite tendency to the whole construct. For 37\% of the German respondents "offering help when they got stuck" is an important requirement for using self-scan checkouts compared with $13 \%$ of the Russian respondents. On the other hand, $38 \%$ of the Russian sample states that not offering help would not be a reason to avoid the technology in contrast to only $17 \%$ of the German sample. Another interesting fact is shown by items SE. 1 and SE.5. Here it is shown that nearly $77 \%$ of the German students would be able to use self-scan checkouts even without the help of others and if no one showed them how to use them. In the Russian sample, only 53\% have such confidence.

As mentioned before, technology anxiety can be one of the biggest problems in relation to self-servicetechnology acceptance (Ostrom et al., 2002) and is the third psychological construct measured in our study. The results lead us to the assumption that there are differences between the German and Russian students, too (Cramer V: 0.180). In general, there is a low level of technology anxiety for both countries ( $M W G: 2.03 ; M W R: 2.35)$. The German students have a lower degree of technology anxiety than the Russian students do. More precisely, we can find the greatest difference between the countries for item TA.8. Of the participants in Germany, 90\% strongly disagreed with the statement "I am not able to keep up with important technological advances". In the Russian sample only $50 \%$ disagreed; $44 \%$ of the participants answered neutrally. Similar differences can be found for item TA.1 ("I am unconfident I can learn technology-related skills"). Of the German students, 95\% are confident about learning technology-related skills, but of the Russian students only $73 \%$ are.

Although both countries are characterized in previous literature by a fairly high level of uncertainty avoidance (R: 75; G: 65), we measured low levels of technology anxiety. The reason for this discrepancy may be the chosen sample of technology-friendly students. However, the proven slightly higher technology anxiety of the Russians is congruent with the expectations from previous research. People in countries with a higher level of uncertainty avoidance, such as Russia, have a lower level of willingness to change their established patterns (Steenkamp et al., 1999) and are more anxious about using new technologies (Park/Jun, 2003).

To sum up and to answer our research questions we state that there are significant differences between Germany and Russia in relation to social pressure, self-efficacy and technology anxiety. We found significant mean value differences for 11 items while the differences for 8 items were not significant. The mean values of social pressure and technology anxiety of the German sample are lower than the Russian ones. Additionally, the results show that the German students have a higher mean for self-efficacy than the Russian students do. The intention to use self-scan checkouts shows similar and slightly positive mean values, indicating that higher sensitivity to social pressure can compensate for lower self-efficacy in a technology-friendly environment.

\section{MANAGERIAL IMPLICATIONS}

This article adds to our understanding of cross-cultural influences on customer appraisal of self-scan technologies. Prior research has shown the effects of self-efficacy, technology anxiety and social pressure on technology acceptance behaviour (Meuter et al., 2005; Eastin, 2002; Meuter et al., 2003; Nysveen et al., 2005). In this article, we further examine self-efficacy, social pressure and technology anxiety as key influencers of technology acceptance in an international comparison. This study shows that people in Germany and Russia are different with respect to these psychological characteristics. It can be argued that Russian customers are more anxious about using self-scan checkouts and are more influenced by important persons than customers in Germany. In fact, we found higher levels of technology anxiety and social pressure for the Russian sample. Furthermore, our findings shed some light on the role of self-efficacy. In general, the German students attained a higher level of selfefficacy. However, a closer look at one separate item shows that more Russian than German students would be confident about using this technology even without help when they become stuck, which is in contrast to the other items. 
Russian customers have a lower degree of self-efficacy and think that they are less able to keep up with technological advances. The results clearly show that firms should find ways to reduce technology anxiety and restore self-efficacy. The key to acquiring more users of self-scan checkouts in countries with a high level of uncertainty avoidance is to reduce the perceived uncertainty. Firms, therefore, should promote their checkouts as a safe way to pay for the products. In Russia, marketing can offer help in a prior stage of the acceptance process to avoid breaking off. Firms wanting to implement self-scan checkouts in Russia have to provide general understandable descriptions of how to use such technology. By doing so, they can reduce technology anxiety.

In Germany, we found a pronounced need for help in case customers become stuck. Firms in Germany should think about offering support or help, which should be clearly visible to the customers. Helpful salespersons or posters showing how to use these technologies can reduce anxiety and make the consumers feel secure. Using such a technology is a relatively new situation to customers. Because of this, managers in Germany as well as in Russia need to implement communication programmes that address technology anxiety and self-efficacy issues. In doing so, these communications may better explain the self-scan-checkout usage and will reassure consumers that using this technology is easy and comfortable. These communication programmes could prospectively be self-help guides outlining successful behaviour or short promotional movies showing how to use self-scan checkouts

The higher sensitivity to social pressure in Russia is a chance for market launch strategies. As a managerial implication, we can think of famous people acting as promoters for self-scan checkouts. Supporting the technologyfriendly environment in Russia can compensate for higher technology anxiety.

\section{LIMITATION AND FUTURE RESEARCH DIRECTIONS}

As with any study, the results should be interpreted with caution for several reasons. First, to maximize internal validity, a hypothetical scenario rather than an actual consumption experience was used as a stimulus. Second, the sample limits the generalizability to other countries of the results. The data came from students of two specific countries (Germany and Russia), and hence generalization to other cultural groups has to be made with care. Third, this study was based on self-reports via questionnaire, thus raising the issue of common method variance and the consistency motif. Fourth, this article only focused on self-efficacy, technology anxiety and social pressure, knowing well that there are further factors influencing the acceptance of technologies, like ease of use, usefulness and relative advantage (Davis, 1989; Rogers, 2003). Future research in natural settings and with a focus on other influencing factors are needed to broaden our understanding of technology acceptance. Further important questions are: "Would the same results emerge for groups with different demographic and socioeconomic characteristics?" and "Which differences exist between different age groups?".

\section{CONCLUSION}

This study has a number of important implications for understanding and dealing with the factors influencing the acceptance of self-scan checkouts. The findings add to the growing body of evidence that shows how people evaluate factors influencing technology acceptance and shows the differences between Germany and Russia, two countries where self-scan checkouts represent a new and innovative technology. The results mentioned show that customers in Germany and Russia should be addressed in different ways and firms planning to implement selfscan checkouts in Germany and Russia cannot easily transfer their business models from a Western market to an Eastern transition market. They have to adapt their marketing strategies and models to the specific national needs.

We found mean but significant differences in the three studied psychological constructs self-efficacy, social pressure and technology anxiety for German and Russian students. The perceived higher social pressure for the Russian group can be an advantage for market launch strategies in a technology-friendly environment. However, the lower levels of self-efficacy as well as the higher levels of technology anxiety in Russia have to be addressed during the implementation of new technologies there. To draw a conclusion we state that besides some differences between Germany and Russia there is a chance for the successful implementation of self-scan checkouts in both countries. This study helps to us understand the differences and leads to adapted market launch strategies. 


\section{AUTHOR INFORMATION}

Jana Schliewe is a Ph.D. student in marketing at Ilmenau University of Technology. She was awarded a degree in media economics at Ilmenau University of Technology in 2008. She received the award for the best theoretical thesis in 2008 for her diploma thesis about the negative emotions of older consumers at the point of sale. Her research focuses on the acceptance of self-service technology, innovation marketing, and target group marketing.

Kerstin Pezoldt, Ph.D., Ilmenau University of Technology, Department of Marketing, is a Professor of Marketing, teaches Marketing Firms, International Marketing and Mass Media Marketing. She has written six books and several articles in reference journals in various areas of consumer behaviour, gender marketing, marketing innovation in small and medium enterprises, international marketing, and marketing of radio and television firms.

\section{REFERENCES}

1. Agarwal, R.; Prasad, J. (1997): The role of innovation characteristics and perceived voluntariness in the acceptance of information technologies, in: Decision Sciences, Vol. 28, pp. 557-582.

2. Anselmsson, J. (2001): Customer-Perceived Service Quality and Technology-Based Self-Service. Lund Business Press, Lund.

3. Aronson, E.; Wilson, T. D.; Akert, R. M. (2008): Sozialpsychologie, $6^{\text {th }}$ Ed., Pearson Studium, Munich.

4. Bandura, A. (1977): Self-efficacy: toward a unifying theory of behavioral change, in: Psychological Review, Vol. 84, pp. 191-215.

5. Bhattacherjee, A. (2000): Acceptance of e-commerce services: the case of electronic brokerages, in: IEEE Transactions on Systems, Man and Cybernetics, Vol. 30, pp. 411-20.

6. Compeau, D.R. and Higgins, C.A. (1995), Computer self efficacy: development of a measure and initial test, in: MIS Quarterly, Vol. 19, pp. 189-211.

7. Compeau, D.; Higgins, C. A.; Huff, S. (1999): Social cognitive theory and individual reactions to computing technology: a longitudinal study, in: MIS Quarterly, Vol. 23, pp. 145-158.

8. Curran, J. M.; Meuter, M. L. (2007): Encouraging existing customers to switch to self-service technologies: put a little fun in their lives, in: Journal of Marketing Theory and Practice, Vol. 15, pp. 283-298.

9. Curran, J. M.; Meuter, M. L.; Surprenant, C. F. (2003): Intentions to use self-service technologies: a confluence of multiple attitudes, in: Journal of Service Research, Vol. 5, pp. 209-224.

10. Davis, F. D. (1989): Perceived usefulness, perceived ease of use, and user acceptance of information technology, in: MIS Quarterly, Vol. 13, pp. 319-340.

11. Davis, F. D. (1993): User acceptance of information technology: system characteristics, user perceptions and behavioural impacts, in: International Journal of Man-Machine-Studies, Vol. 38, pp. 475-487.

12. Eastin, M. S. (2002): Diffusion of e-commerce: an analysis of the adoption of four e-commerce activities, in: Telematics and Informatics, Vol. 19, pp. 251-267.

13. Featherman, M. S.; Pavlou, P. A. (2003): Predicting e-services adoption: a perceived risk facets perspective, in: International Journal of Human-Computer Studies, Vol. 59, pp. 451-474.

14. Fishbein, M.; Ajzen, I. (1975): Belief Attitude, Intention, Behavior: An Introduction to Theory and Research. Reading, MA: Addison-Wesley.

15. Hofstede, G. (2001): Culture's Consequences: Comparing Values, Behaviours, Institutions, and Organizations across Nations, $2^{\text {nd }}$ Ed., Sage, London.

16. Hung, S.-Y.; Ku, C.-Y.; Chang, C.-M. (2002): Empirical test of a WAP adoption model, working paper, Department of Information Management, National Chung Cheng University.

17. Igbaria, M.; Parasuraman, S. (1989): A path analytic study of individual characteristics, computer anxiety and attitudes toward microcomputers, in: Journal of Management, Vol. 15, pp. 373-388.

18. Karahanna, E.; Straub, D. W.; Chervany, N. L. (1999): Information technology adoption across time: a cross-sectional comparison of pre-adoption and post-adoption beliefs, in: MIS Quarterly, Vol. 23, pp. 183213.

19. Kim, J.; Forsythe, S. (2008): Adoption of virtual try-on technology for online apparel shopping, in: Journal of Interactive Marketing, Vol. 22, pp. 45-59. 
20. Lim, K. H.; Leung, K.; Sia, C. L.; Lee, M. K. (2004): Is eCommerce boundary-less? Effects of individualism-collectivism and uncertainty avoidance on Internet shopping, in: Journal of International Business Studies, Vol. 35, No. 6, pp. 545-559.

21. Lockett, A.; Littler, D. (1997): The adoption of direct banking services, in: Journal of Marketing Management, Vol. 13, pp. 791-811.

22. Meuter, M. L.; Bitner, M. J.; Ostrom, A. L.; Brown, S. W. (2005): Choosing among alternative service delivery modes: an investigation of customer trial of self-service technologies, in: Journal of Marketing, Vol. 69, pp. 61-83.

23. Meuter, M. L.; Ostrom, A. L.; Bitner, M. J.; Roundtree, R. (2003): The influence of technology anxiety on consumer use and experiences with self-service technologies, in: Journal of Business Research, Vol. 56, pp. 899-906.

24. Meuter, M. L.; Ostrom, A. L.; Roundtree, R.; Bitner, M. J. (2000): Self-service technologies: understanding customer satisfaction with technology-based service encounters, in: Journal of Marketing, Vol. 64, pp. 5064.

25. Mueller, S.; Gelbrich, K. (2004): Interkulturelles Marketing. Munich.

26. Nilsson, D. (2007): A cross-cultural comparison of self-service technology use, in: European Journal of Marketing, Vol. 41, pp. 367-381.

27. Nysveen, H.; Pedersen, P. E.; Thorbjørnsen, H. (2005): Explaining intention to use mobile chat services: moderating effects of gender, in: Journal of Consumer Marketing, Vol. 22, pp. 247-256.

28. Ostrom, A. L.; Bitner, M. J.; Meuter, M. L. (2002): Self-service technologies, in: Rust, R.; Kannan P.K. (Eds.): E-Service: New Directions in Theory and Practice. Armonk, New York, pp. 45-64.

29. Park, C.; Jun, J. K. (2003): A cross-cultural comparison of internet buying behavior, in: International Marketing Review, Vol. 20, pp. 534-553.

30. Pedersen, P. E. (2005): Adoption of mobile Internet services: an exploratory study of mobile commerce early adopters, in: Journal of Organizational Computing and Electronic Commerce, Vol. 15, No. 2, pp. 203-222.

31. Robertson, T. S. (1967): The process of innovation and the diffusion of innovation, in: Journal of Marketing, Vol. 31, pp. 14-19.

32. $\quad$ Rogers, E. M. (2003): Diffusion of Innovations, $5^{\text {th }}$ Ed., Free Press, New York.

33. Rogers, E. M.; Shoemaker, F. F (1971): Communication of Innovation, $2^{\text {nd }}$ Ed., Free Press, New York.

34. Rose, J. D. (2007): Predicting Mature Consumers' Attitudes towards Use of Self-Service Technologies in the Financial Service Context. University of Southern Queensland, Queensland

35. Schepers, J.; Wetzels, M. (2006): A meta-analysis of the technology acceptance model: investigating subjective norms and moderation effects, in: The International Journal of Information \& Management, Vol. 44, pp. 90-103.

36. Schmidt, S. (2004): Der russische Konsument. OWC, Muenster.

37. Steenkamp, J.-B. E. M.; Hofstede, F.; Wedel, M. (1999): A cross-national investigation into the individual and national cultural antecedents of consumer innovativeness, in: Journal of Marketing, Vol. 63, No. 2, pp. 55-69.

38. Van Everdingen, Y. M.; Waarts, E. (2003): The effect of national culture on the adoption of innovations, in: Marketing Letters, Vol. 14, No. 3, pp. 217-232.

39. Venkatesh, V.; Davis, F. D. (2000): A theoretical extension of the technology acceptance model: four longitudinal field studies, in: Management Science, Vol. 46, pp. 186-204.

40. Wincor Nixdorf (2007): Erste Installation in Elektrofachmarkt: Saturn Ingolstadt installiert Self-CheckoutSysteme von Wincor Nixdorf, http://www.wincornixdorf.com/internet/site DE/DE/WincorNixdorf/Press/pressreleases/2007/Saturn.html?nn=65156.

41. World Bank (2010): Russian Economic Report 21, http://web.worldbank.org/WBSITE/EXTERNAL/COUNTRIES/ECAEXT/RUSSIANFEDERATIONEXT N/0,,contentMDK:22513909 menuPK:305605 pagePK:2865066 piPK:2865079 theSitePK:305600,00.ht ml.

42. Yeniyurt, S.; Townsend, J. D. (2003): Does culture explain acceptance of new products in a country? in: International Marketing Review, Vol. 20, No. 4, pp. 377-397.

43. Yoh, E.; Damhorst, M. L.; Sapp, S.; Laczniak, R. (2003): Consumer adoption of the Internet: the case of apparel shopping, in: Psychology \& Marketing, Vol. 20, pp. 1095-1118. 


\section{NOTES}

